\title{
Rosary nodules of the legs
}

\author{
Ahlam Abdou*, Ilham El Meknassi, Nadia Ismaili, Leila Benzekri, Karima Senouci and Badredine Hassam \\ Department of Dermatology, CHU IBN SINA, Ibn Sina Hospital University, BP 6527, Rabat, Maroc
}

\begin{abstract}
Segmental neurofibromatosis is a rare genodermatosis secondary to post zygotic somatic mutation of the NF1 gene. It may be accompanied by neurological and skeletal complications. We report the caseof a 13 years old child with bilateral segmental neurofibromatosis on the thighs and legs. Clinical monitoring was proposed each year and genetic counseling was lavished.
\end{abstract}

\section{Introduction}

Segmental neurofibromatosis a rare genodermatosis characterized by segmental symptoms. We report a case who presented painful and bilateral nodules arranged in series.

\section{Observation}

The child HJ, 15 years old, consulting for non pruritic painless swelling localized at gradually lower members that increase in size since 13 years old. The patient had no notion of consanguinity or similar cases in the family. Clinical examination found multiple subcutaneous bilateral nodules with a facing skin flesh-colored, grouped rosary on the thighs and medial sides of the legs. The rest of examination shows both lentigines and coffee with milk spots localized in the left flank without axillaire location (Figures 1-3). There was no plexiform tumors or osteo-articular abnormalities or ophthalmic neurologiques signs. Ocular examination didn't found Lisch nodules. We discussed the diagnosis of schwannoma, a rare lipomatosis or variant neurofibromatosis. Ultrasound soft tissue revealed multiple tissue pictures dented measuring $20 \mathrm{~mm}$ to $36 \mathrm{~mm}$ in diameter, resembling to a nervous origin. The Histopathological exam of the nodule was in favor of a neurofibroma (Figure 4). The brain scan and X-rays of long

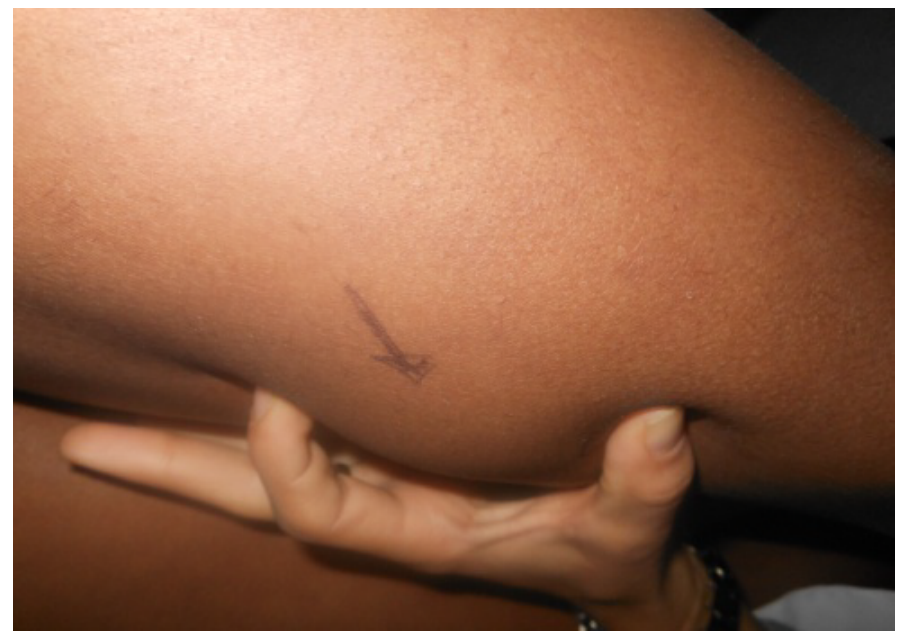

Figure 1. Nodule of the thigh. bones have not objectified anomalies. Segmental neurofibromatosis was detention. Clinical monitoring has been proposed every year.

\section{Discussion}

Segmental neurofibromatosis is extremely rare: 0.0014 to $0.002 \%$, with female predominanceat average 30 years old [1]. This is a somatic mutation postzygotic the NF1 gene. The risk of transmission is very low (1 in 18 cases) [1,2]. Segmental localization is due to a phenomenon of late somatic mosaicism. Lesions are usually unilateral. The particularityof our observation is represented by the following atypical clinical appearance of bilateral lesions in a stringnerve pathway. Serious complications such as scoliosis, learning disorders, hematologicalhave been reported [3]. The care of patients is not codified. In absence of a study regarding therisks involved in the case of segmental

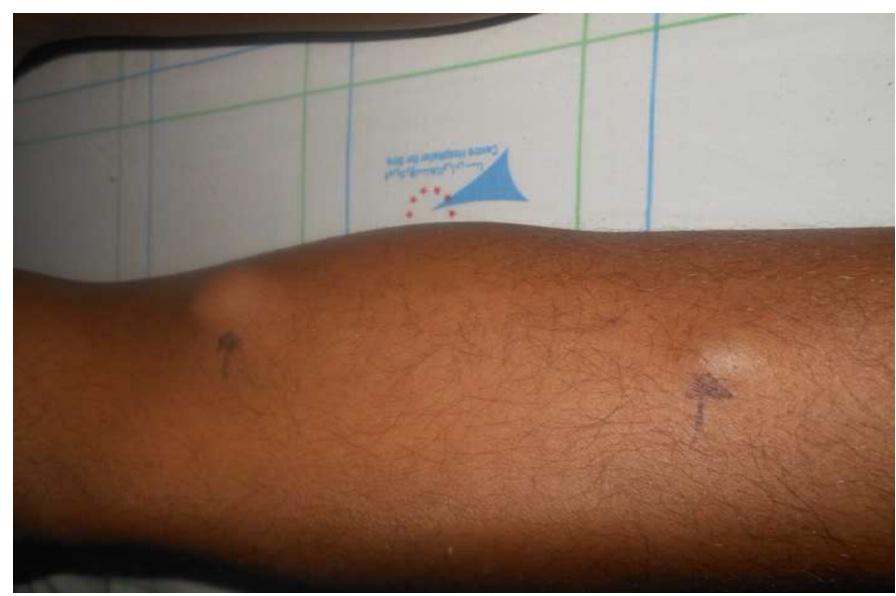

Figure 2. Nodules rosary at the leg $(2 \mathrm{~cm} / 2 \mathrm{~cm})$.

Correspondence to: Ahlam Abdou, Department of Dermatology, Ibn Sina Hospital University, 1 Bir Rami Ouest Kénitra, 14090, Maroc, Tel: 00212671568343; E-mail: sophialondon9@hotmail.fr, ahlam.siham.abdou@gmail.com

Key words: rosary, neurofibromatosis, subcutaneous nodules

Received: June 21, 2015; Accepted: July 25, 2015; Published: July 28, 2015 


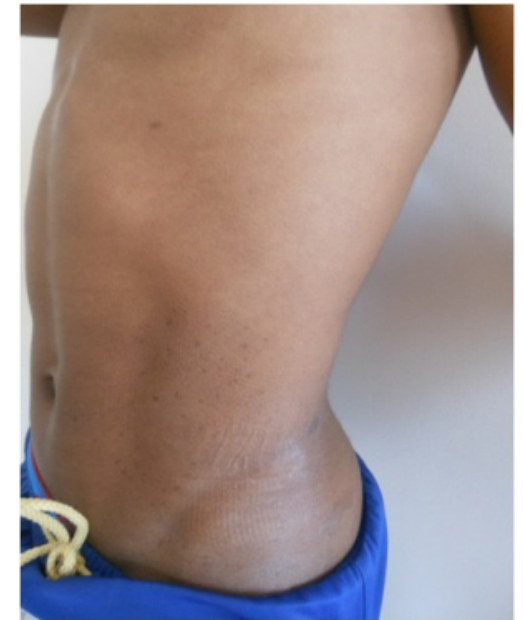

Figure 3. Spots lattes the flank.

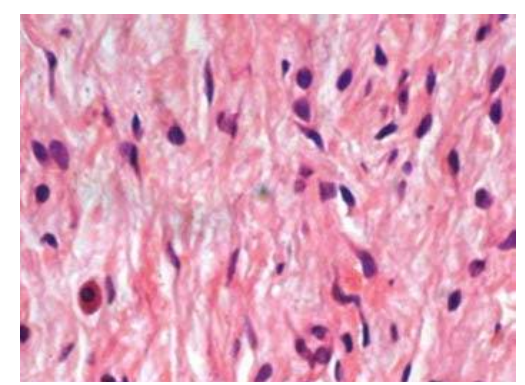

Figure 4. Proliferation of nerve fibers entangled in the connective tissue. neurofibromatosis, it seems justified to provide an initial assessment andclinical monitoring. Genetic counseling should be done.

\section{References}

1. Saurat JH, Lachapelle JM, Lipsker D, Thomas L (2009) Saurat (5thedn), Masson France. Allanore L, P. Wolkenstein P (Eds.), Neurofibromatosi: 10,4.

2. Galhotra V, Sheikh S, Jindal S, Singla A (2014) Segmental neurofibromatosis. Indian J Dent 5: 166-169. [Crossref]

3. Sobjanek M, Dobosz-Kawałko M, Michajłowski I, Peksa R, Nowicki R (2014) Segmental neurofibromatosis. Postepy Dermatol Alergol 31: 410-412.

Copyright: $\odot 2015$ Abdou A. This is an open-access article distributed under the terms of the Creative Commons Attribution License, which permits unrestricted use, distribution, and reproduction in any medium, provided the original author and source are credited. 